\title{
Endoscopic Mucosal Resection of gastric dysplastic lesion by band ligation technique
}

Umid Kumar Shrestha, MD, PhD

DOI Name

http://dx.doi.org/10.3126/jaim.v6i1.18312

\section{Keywords}

Gastric dysplastic lesion, Endoscopic Mucosal

Resection

\section{Citation}

Umid Kumar Shrestha. Endoscopic Mucosal Resection of gastric dysplastic lesion by band ligation technique. Journal of Advances in Internal Medicine 2017;06(01):9-10.

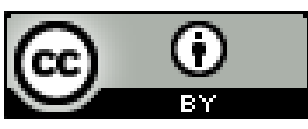

This work is licensed under a Creative Commons Attribution 3.0 Unported License.

\section{MEDICAL IMAGE}

A 55 years old female presented with the pain in the epigastric region for 6 months. The upper gastrointestinal endoscopy revealed slightly raised mucosal lesion in the antrum; the biopsy from the lesion showed the high-grade dysplasia. The CT scan of abdomen was done, which was normal. The decision was made to perform Endoscopic Mucosal Resection (EMR) of the gastric dysplastic lesion by band ligation technique (Figure).

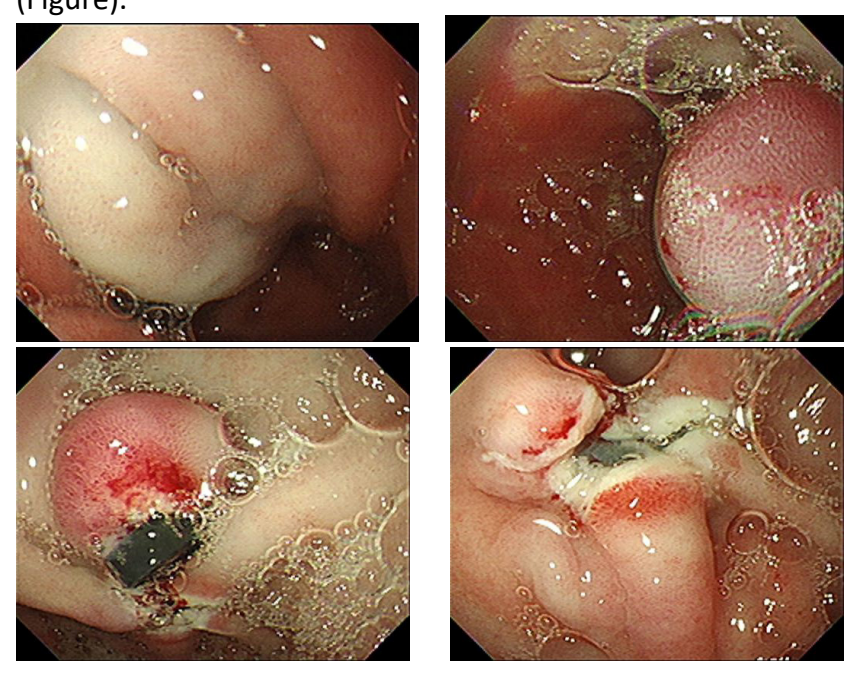

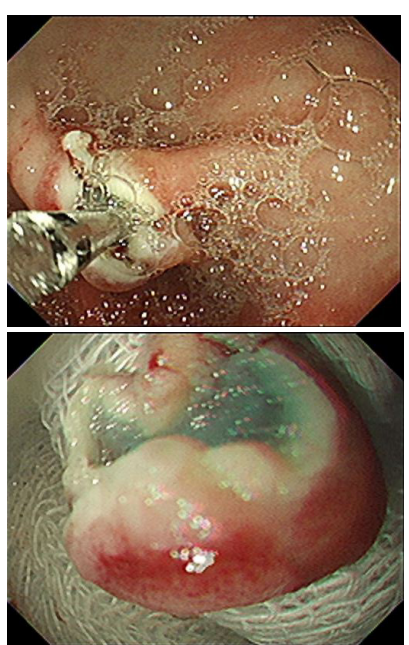

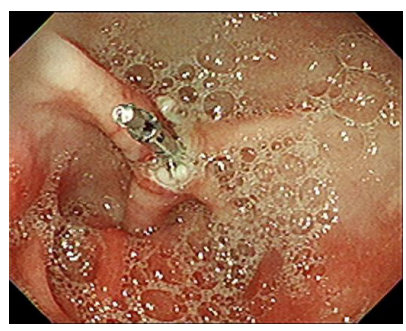

Figure: Endoscopic mucosal resection (EMR) of gastric dysplastic lesion by band ligation technique Submucosal injection of $10 \mathrm{ml}$ of Normal Saline along with Epinephrine $(1: 10,000)$ and Methylene Blue was given in the dysplastic lesion in the antrum in the pre-pyloric region

\footnotetext{
* Corresponding author Umid Kumar Shrestha, MD, PhD Professor, Department of Medicine

Manipal College of Medical Sciences, Pokhara, Nepal

Email: umidshrestha@gmail.com
} 
of the stomach. Suction was applied in the lesion to create a pseduopolyp; the band was placed at the base of the pseudopolyp. The pseudopolyp was then resected using snare electrocautery below the band. The hemoclip was applied in the defect area of the lesion. The resected tissue was retrieved with the Roth's snare. The post-procedure condition of the patient was uneventful. The histopathology report was consistent with the high-grade gastric epithelial dysplasia.

There are two most important EMR techniques, the cap technique and the band ligation technique. ${ }^{1}$ Among them, band ligation has been used for the EMR of Barrett's esophagus. ${ }^{1}$ In case of gastric high grade dysplasia, the band ligation technique of EMR has not been established, but in our case, gastric high-grade dysplasia was resected successfully by EMR. On follow-up endoscopy after six months and one year, the patient was asymptomatic and HPE did not show any evidence of dysplasia. Because of the potential for progression to carcinoma and the coexistence of carcinoma, the management of high-grade dysplasia of stomach require endoscopic resection. ${ }^{2}$ However, after EMR of gastric dysplasia, close follow-up surveillance should be performed for all patients. ${ }^{3}$

\section{REFERENCE:}

1. Tomizawa Y, lyer PG, Wong LM, et al. Safety of Endoscopic Mucosal Resection for Barrett's Esophagus. Am J Gastroenterol, 2013;108:1440-7.

2. Sung JK. Diagnosis and management of gastric dysplasia. Korean J Intern Med. 2016; 31:201-9.

3. Baek DH, Kim GH, Park DY, et al. Gastric epithelial dysplasia: characteristics and long-term follow-up results after endoscopic resection according to morphological categorization. BMC Gastroenterology 2015;15:17. 